\title{
Violências urbanas em França: excepção ou novíssima guerra?*
}

\author{
Daniel Marcelino Rodrigues ${ }^{1}$ \\ "La misère mène à la révolte ou à la soumission." \\ Dominique Blondeau, Les Errantes \\ "L'insurrection confine à l'esprit, lémeute à l'estomac." \\ Victor Hugo, Les Misérables
}

\section{Resumo}

As notícias relativas a motins nos subúrbios das cidades francesas são hoje em dia frequentes. Este artigo procura ser uma análise crítica à questão das violências urbanas (no plural) no contexto francês à luz do conceito de "novíssimas guerras" defendido por Tatiana Moura. Através da sua definição assim com da observação das falhas estruturais que estão na sua origem e dos mecanismos de resposta a este fenómeno, o artigo demonstra a especificidade destas violências urbanas à la française.

Palavras-chave: Violências urbanas. França. Novíssimas guerras.

\section{Introdução}

Quando pensamos em violência urbana no espaço nacional francês, recordamos com alguma naturalidade os acontecimentos do Outono de 2005, pouco

* Recebido em 24.09.2010.

Aprovado em 06.12.2010.

1 Universidade de Coimbra. É licenciado em História pela Faculdade de Letras da mesma universidade. A sua investigação presente debruça-se sobre questões ligadas ao federalismo, regionalismo(s), etnonacionalismo, União Europeia, Rússia e filosofia política. As suas publicações incluem: "Education, science and social darwinism in Nazi Germany: formation of a society based on the myth of blood and the superiority of Aryan race" (no prelo); "The Polish-Lithuanian Commonwealth: A New Look on a Peculiar Type of Federalism" (no prelo, revista "Regionines studijos"); "Fortress Europe: Restrictive Immigration Policies as a Trigger of Potential Conflict(s)?” (2009, em co-autoria). 
mais de um mês de motins pautado por acções nocturnas visando a destruição de bens privados, a resistência às forças da ordem e o ataque a símbolos da República. Qual foi a origem desde movimento? Será ele meramente fortuito e imprevisto ou poderá uma análise mais profunda dotar o seu observador de instrumentos válidos para a sua compreensão? Apesar de, temporalmente, os motins urbanos de 2005 terem sido invulgares, é de notar que este tipo de fenómeno não apresentou aqui a sua primeira manifestação. Um dos objectivos deste estudo consiste precisamente em situar no tempo a origem desta nova forma de contestação, desta forma de violência urbana, e, por conseguinte, defini-la de forma a poder entender-se em toda a sua amplitude.

Porém, e voltando aos motins do Outono de 2005, é de salientar a atenção que os órgãos de comunicação estrangeiros (refiro-me aos media não franceses) prestaram ao fenómeno, em especial ao "fracasso" do modelo de integração republicano francês assim como às possíveis repercussões daquela espiral de violência noutros contextos nacionais. Poderá o conceito de "novíssimas guerras" desenvolvido por Tatiana Moura aplicar-se a este caso? Ou serão as violências urbanas à la française um caso particular no seio do quadro de conflitualidade urbana generalizada a nível mundial?

\section{0 que são as violências urbanas à la française?}

Em termos de estudo e a favor de uma certa coerência metodológica, a presente linha de análise não vai tomar como ponto de partida a definição institucionalizada de "violências urbanas", sendo esta a conclusão lógica do processo analítico que se apresentará de seguida. Desta forma, é necessário justificar o recurso ao conceito de "violências urbanas" por oposição a "violência urbana". A diferenciação poderá parecer ao leitor mais distraído desajustada. Contudo, o uso do conceito de "violência urbana" no singular afigura-se incorrecto já que não existe uma única violência urbana mas sim um conjunto de violências urbanas, tantas quantas as suas manifestações. Neste sentido, os motins urbanos não podem abranger este fenómeno no seu todo nem tão pouco ser identificados como tal. Os motins urbanos assumem somente uma das suas faces, complementados por uma série de compor- 
tamentos também eles considerados agressivos para a sociedade e a ordem vigente. Importante será ainda verificar a pertinência semântica do conceito de "violências urbanas". Eric Macé é, a este respeito, peremptório. Segundo ele, o termo "urbano" remete para um determinado contexto, a urbanização ou o urbanismo como causa das violências, enquanto que a realidade é mais profunda (1999, p. 61). A causa deste fenómeno está bem identificada e tem tanto de socio-económico, cultural e psicológico como de género e etário. A utilização do vocábulo "urbano" acaba por indiciar como espaços propícios a este tipo de violência os bairros periféricos e os subúrbios das cidades, as banlieues. Institucionalizada pelos Renseignements Géné$\operatorname{raux}(\mathrm{RG})^{2}$, a expressão "violências urbanas" não é reconhecida em termos judiciais nem tão pouco pelas estatísticas das forças da ordem respeitantes a crimes e deli$\operatorname{tos}^{3}$. Tal não significa que esta forma de contestação fique impune. Porém, qualquer acção policial e penal tem apenas como objecto determinadas manifestações destas violências urbanas já que nem todas, ainda que incluídas neste conceito mais genérico, são consideradas crimes. As “incivilidades” são um claro exemplo de comportamentos vistos como impróprios, quiçá desordeiros e ofensivos para a ordem pública e a comunidade, sendo raramente vistos como crimes ou delitos ${ }^{4}$. Cuspir em público, pequenas degradações do património, insultos, são consideradas “incivilidades" e, em simultâneo, elementos que caracterizam os jovens dos subúrbios.

Independentemente da sua nomenclatura e à semelhança de qualquer movimento de contestação social violenta, as violências urbanas têm as suas raízes num forte sentimento de injustiça, caracterizado pela exigência de "respeito" pelas

2 "Chargés de la défense des institutions et de l'ordre social contre toutes les « menaces» de subversion, ils sont spécialisés dans la surveillance des mouvements sociaux et politiques " contestataires »." (BONELLI, 2001, p. 95).

3 "Aucun individu ne sera poursuivi ni traduit devant une juridiction pour avoir commis une ou des « violences urbaines »." (BAUER et al., 2006, p. 7).

4 "Les incivilités sont des comportements non profitables, non conflictuels mais frictionnels, peu organisés et très visibles. La seconde caractéristique, qui découle en partie de la première, est qu'elles ne sont guère réprouvées : elles sont très rarement jugées graves et condamnables si on les compare à d'autres comportements déviants. Cela rend difficile de se mobiliser collectivement contre elles. Enfin, dernière caractéristique, les désordres sont publics, c'est-à-dire qu'ils se déroulent dans les lieux publics ou qu'ils rendent publics des lieux privés [...] : ils se donnent à voir. Il s'agit donc de tensions sur les modes d’occupation de l'espace et sur la négociation des relations interindividuelles." (ROCHÉ, 2002, p. 48). 
autoridades, em especial pelas forças da ordem, acusadas de racismo e de abuso do recurso à força. Não é por acaso que os motins urbanos têm geralmente na sua base a morte ou o ferimento de um ou mais jovens do bairro em causa, em relação com uma operação policial ou a suspeita da sua ocorrência. É neste seguimento que as violências urbanas devem ser inseridas no âmbito mais lato das violências sociais. Estas exprimem-se através de três níveis complementares: a crise, a estratégia e o significado (FISCHER, 2003, p.159). O primeiro remete para o recurso à violência enquanto expressão do mau funcionamento das instituições e da sociedade. O segundo observa a instrumentalização da violência que, com maior ou menor organização, apenas subsiste através da existência de um objectivo claro. Finalmente, o terceiro nível das violências sociais tem por base a falta de correspondência entre o que é esperado e o que é recebido, mormente no que diz respeito às reivindicações sociais. Naturalmente, todos estes níveis estão interligados e encontram-se presentes no caso aqui analisado.

Uma das causas centrais, se não a principal causa das violências urbanas, tem a ver com a decomposição do operariado e das antigas formas de polarização social derivadas da entrada das sociedades ocidentais na era pós-industrial e da caducidade do taylorismo. O estudo de Christian Bachmann e Nicole Le Guennec (2002) é, a este respeito, indispensável. As actuais violências urbanas divergem da antiga luta do proletariado contra o patronato, é o fim da cintura vermelha onde a marginalização era o resultado de uma lógica de classes. Progressivamente, os actores deste novo tipo de violência(s) vão sendo identificados através da origem étnica a despeito do velho reconhecimento pela classe social. A postura das forças da ordem e das outras entidades republicanas (por ex. a escola), que se desejaria irrepreensível e exemplar, acaba por conduzir ao reforço do sentimento de discriminação por parte dos jovens de origem magrebina e africana ${ }^{5}$. A cidadania e a igualdade, essências do modelo republicano de integração, apresentam-se-lhes como mera demagogia sem real aplicação no seu quotidiano. Não é, pois, por acaso que os símbolos da República são atingidos pela fúria destes jovens aquando dos motins.

5 "C'est ce que l'on appelle en France le "contrôle au faciès" et le problème du "racisme professionnel” des policiers." (MUCCHIELLI, 2002, p. 9). 
Em termos conceptuais, poder-se-á afirmar que as "violências urbanas" à la française consistem em actos violentos colectivos levados a cabo por jovens e pré-adolescentes, geralmente do sexo masculino, oriundos da imigração magrebina e sub-sahariana e vivendo nos bairros urbanos periféricos (banlieues). Estes actores estão, usualmente, desempregados ou inactivos, em situação de emprego precário ou de aprendizagem, ou em variantes educativas profissionalizantes pouco prezadas. Os actos cometidos assumem várias dimensões: as “incivilidades”, as delinquentes e as anti-institucionais. No entanto, e contrariamente a outras situações de violência urbana, a violência que assola as urbes francesas apenas em casos excepcionais atinge um grau tão extremo quanto é a morte de um indivíduo envolvido na mesma. Não se encontra estruturada por uma qualquer formação política. Situações como as que subsistem nas cidades norte-americanas ou brasileiras e fazem parte do seu dia-a-dia não têm real visibilidade em França (CRETTIEZ; SOMMIER, 2006, p. 30; MACÉ, 1999, p. 60).

\section{Violências urbanas e criminalidade}

Serão estas "violências urbanas" totalmente imprevisíveis? Ou existirão indicadores que possibilitem a sua prevenção? A resposta não é, a este respeito, inequívoca. Se, por um lado, existem de facto elementos que permitem antever a expansão de um sentimento de insatisfação latente semi-adormecido no seio de determinados sectores da sociedade; por outro lado, a existir esse sentimento, é difícil às autoridades prever o momento exacto em que o barril de pólvora pode explodir ${ }^{6}$. Estas têm, contudo, várias formas de medição das violências urbanas (a escala Bui-Trong, o SAIVU ${ }^{7}$, o INVU ${ }^{8}$ e os inquéritos de vitimização) (BAUER,

\footnotetext{
6 "Fortement probables : la situation des banlieues est instable, pour des raisons structurelles : le chômage, le cumul des problèmes sociaux, l'affaissement des services publics, l'omniprésente violence quotidienne... Mais totalement imprévisibles : tout peut basculer à tout moment. Il suffit que le point d'équilibre se déplace : le moindre micro-évènement local peut mettre le feu au quartier, et rien ne peut arrêter la machine infernale." (BACHMANN \& LE GUENNEC, 2002, p. 357-358).

7 SAIVU - Système d'analyse informatique des violences urbaines (em português: Sistema de análise informático das violências urbanas).

8 INVU - Indicateur national des violences urbaines (em português: Indicador nacional das violências urbanas).
} 
2006, p. 11-21), com todas as falhas reais de qualquer estatística, complementadas através do estabelecimento de uma cartografia dos bairros sensíveis. Curiosamente, a escala Bui-Trong, elemento de referência nesta avaliação por parte das autoridades policiais, não tem como primeiro objectivo a violência em termos globais mas sim os graus de tensão entre jovens e representantes do Estado, em particular a polícia (MUCCHIELLI, 2001, p. 6).

Quadro 1: Resumo da escala de avaliação das violências urbanas das RG, ou escala BuiTrong

\begin{tabular}{|c|l|}
\hline Graus & Formas características \\
\hline 1 & $\begin{array}{l}\text { Vandalismo; razias; rodeos de carros roubados; confrontos entre } \\
\text { grupos }\end{array}$ \\
\hline 2 & $\begin{array}{l}\text { Tensões com os porteiros; insultos aos adultos, professores e polícias; } \\
\text { pequeno vandalismo contra bens públicos (escolas, esquadras de } \\
\text { polícia, salões municipais, ...) }\end{array}$ \\
\hline 3 & $\begin{array}{l}\text { Agressões físicas a agentes públicos (revisores, bombeiros, militares, } \\
\text { professores, ...) }\end{array}$ \\
\hline 4 & $\begin{array}{l}\text { Agrupamentos ameaçadores para as forças da ordem; lapidação de } \\
\text { carros-patrulha }\end{array}$ \\
\hline 5 & $\begin{array}{l}\text { Invasão de esquadras de polícia; tráficos diversos visíveis (droga, } \\
\text { venda de material roubado) }\end{array}$ \\
\hline 6 & $\begin{array}{l}\text { Agressões físicas a membros das forças da ordem; ataques a } \\
\text { esquadras de polícia; emboscadas }\end{array}$ \\
\hline 7 & $\begin{array}{l}\text { Vandalismo massivo (destruição de montras, incêndio de veículos, } \\
\text { lançamento de cocktails Molotov) levado a cabo por grupos de 15 a } \\
30 \text { jovens, num curto espaço de tempo, sem confronto directo com } \\
\text { as forças da ordem }\end{array}$ \\
\hline 8 & $\begin{array}{l}\text { Destruição e pilhagem; agressões de particulares; guerrilha com } \\
\text { as forças da ordem várias noites seguidas por grupos de 50 a 200 } \\
\text { jovens; motim }\end{array}$ \\
\hline
\end{tabular}

Fonte: Bonelli (2001, p. 100) e Mucchielli (2001, p. 7) (adaptado). 
Através da análise da escala Bui-Trong, verifica-se a exclusiva identificação de facetas das violências urbanas passíveis de perseguição judicial. As incivilidades surgem num plano secundário, semi-escondidas por aqueles actos. Porém, as incivilidades "legais", apanágio dos jovens irreverentes por natureza, surgem frequentemente associadas à prática de acções violentas concretas e à delinquência. A passagem de umas às outras aparece como natural, não existindo uma fronteira clara entre ambas 9 . Tal acaba por reforçar a percepção generalizada de que a juventude recorre à violência não só com intentos destrutivos, emocionais ou, inclusive, lúdicos mas também como meio de garantir a subsistência de uma economia subterrânea. É nesta sequência que alguns autores se referem às violências urbanas ligando-as directa ou indirectamente à criminalidade organizada e ao tráfico de droga $^{10}$. O elo de ligação directa prende-se com o recurso a este tipo de violências como forma de manter fora do "território" todos os indesejáveis, desde os rivais e concorrentes no abastecimento de droga à cité até às forças da ordem. Indirectamente, a quietude e a ordem aparentes de uma zona considerada sensível pelas autoridades poderá indiciar o desenvolvimento de uma economia subterrânea organizada, adversa às manifestações mais efusivas de uma certa juventude cujos resultados, a saber a presença das forças da ordem, é de todo indesejável (BAUER et al., 2006, p. 46-48). É o que Jérôme Pierrat (2006, p.21) chama de "paix criminelle", ou seja, paz criminosa. Foi assim que durante os motins do Outono de 2005 inúmeras banlieues consideradas sensíveis e susceptíveis de explodir de um dia para o outro se mantiveram sossegadas ${ }^{11}$.

9 "Ainsi, le passage de la violence traditionnelle à l'école - le chahut, c'est-à-dire la violence normale - à la violence collective inédite, pathologique, est de plus en plus fréquent : les frontières entre ces deux formes de violence sont devenues poreuses." (BAILLET, 2000, p. 23).

10 "Leur «best-seller», c'est le trafic de stupéfiants, qui représente $80 \%$ de l'économie souterraine des banlieues. Le cannabis, c'est 10 milliards d'euros de chiffre d'affaires annuel. Les mafias des cités en importent entre 700 et 1000 tonnes par an. C'est la première vache à lait des gars de banlieue, avec, dans une moindre mesure, la cocaïne, l'héroïne, l'ecstasy [...]" (NESSI, 2006).

11 "Les cités les plus criminogènes nont pas participé aux émeutes. Elles sont restées curieusement calmes. Les grosses cités pourvoyeuses de stupéfiants, comme dans les Hautsde-Seine, nont pas bougé. Dans le 93, les cités qui fournissent les braqueurs, les casseurs, les cambrioleurs, ne se sont pas enflammées. Ceux qui ont des grosses affaires avaient autre chose à faire que brûler des voitures ou attaquer des cars de CRS." (NESSI, 2006). 
A somar ao tráfico de droga está a questão do armamento. Com a queda do muro de Berlim em 1989, o vasto mercado do Leste europeu trouxe uma oportunidade única e até aí inigualável. Fornecedores "oficiais" da ex-URSS, os países do Pacto de Varsóvia viram-se obrigados a reorientar o destino da sua produção e a ambição desmesurada de certos delinquentes dos subúrbios ocidentais, entre os quais os franceses, facilitaram o seu escoamento. As várias guerras nos Balcãs, na década de 1990, vieram apenas reforçar o estatuto da Europa de Leste enquanto mercado abastecedor de armas ligeiras e de guerra. Todavia, apesar da existência de redes transnacionais de tráfico de armas, tanto os elementos das forças da ordem como os próprios delinquentes negam-na sem contudo negarem a circulação de armas nos meandros do crime ${ }^{12}$.

Os dois tráficos aqui referidos, de droga e de armas, aliados ao desenvolvimento do crime organizado remetem visivelmente para o conceito de "novíssimas guerras", como definido por Tatiana Moura (2005, p. 83) em virtude do seu estudo do caso brasileiro. Mas estar-se-á realmente perante esse cenário nas banlieues francesas? Ainda que a proliferação de armas ligeiras e de guerra seja, no contexto aqui analisado, real, não existe uma disseminação da violência armada directa nem taxas de mortalidade por armas de fogo elevadas, à semelhança do que sucede em cidades como o Rio de Janeiro, Joanesburgo ou San Salvador, a ponto de poder falar-se de uma guerra civil organizada. Porém, e seguindo a argumentação apresentada por Tatiana Moura, este tipo de violência é o resultado de uma combinação de factores que não se confina em exclusivo aquelas duas características. Assim, para além delas, deve-se verificar

\footnotetext{
12 “" Il n’y a pas non plus de grosses caches d’armes qui dorment dans les cités, précise un membre du Groupe d'intervention régionale du Val-de-Marne. Ce sont plutôt des achats ponctuels en vue d'un coup ou pour mener à bien certaines affaires illégales. » L’ex-Yougoslavie, les marchés de Bucarest ou de Sofia, où la kalachnikov se négocie 100 euros, ne sont pas loin. "Il n’y a pas de trafics d'armes organisés. C’est du fantasme. En revanche, t'as plein de petites filières pour t'en procurer, analyse un voyou de cité du 94 . Les armes de guerre viennent quasiment toutes de l'Est. Dans les banlieues où ils habitent, t'as des "Yougos" qui nont pas de prise direct avec les grands voyous. Mais ils connaissent un môme du coin qui du coup leur ramène ses potes et c'est comme ça que t'as des petits mecs qui se retrouvent avec des armes lourdes. "” (PIERRAT, 2006, p. 32-33).
} 
[...] a persistência de elevados níveis de desigualdade social, as taxas baixas ou negativas de crescimento económico, o elevado índice de desemprego e de emprego precário, o rápido crescimento das grandes cidades e das áreas metropolitanas, a homogeneização e inflação das expectativas dos jovens que nascem nas comunidades mais pobres, a ausência ou fragilidade de infra-estruturas urbanas básicas, de serviços sociais básicos e de organizações da sociedade civil em bairros mais pobres, [...] a cultura da violência mantida e perpetuada pelo crime organizado e pelos meios de comunicação e, finalmente, o baixo nível de eficácia da polícia e de outras instituições do sistema de justiça criminal (MOURA, 2005, p. 83-84).

São estas questões que vão ser analisadas no capítulo seguinte, com particular ênfase nas causas socio-económicas e culturais das violências urbanas francesas.

\section{Causas socio-económicas das violências urbanas em França}

Como anteriormente referido, as violências urbanas à la française têm como principal causa factores de índole socio-económica que, não sendo exclusivos, são com toda a certeza os mais relevantes. Deste modo, é necessário percepcionar de que forma se chegou a esta forma de contestação.

Para retomar a ideia segunda a qual a decomposição do operariado e das antigas formas de polarização social conduziram a este fenómeno, verifica-se que as classes populares, ou operárias, entraram neste período pós-industrial através de um processo marcado pela sua pauperização, fragilização e precarização (BEAUD; PIALOUX, 2002, p. 220). A desindustrialização e a entrada numa economia de serviços tornaram o emprego não qualificado precário e o desemprego estrutural (AVENEL, 2004, p. 26-27). Os jovens dos subúrbios são os primeiros atingidos por esta situação e, recusando categoricamente a submissão à semelhança dos seus pais, procuram formas de expressão próprias com o intuito de verem reconhecidas as suas diferenças pela sociedade que teima em rejeitá-los. As violências urbanas são uma das suas faces, o hip-hop é outra. Citando Dubet, Laurent Mucchielli (1999, p. 16) alude, a este respeito, a "îlots de résistance” caracterizados por um conteúdo 
cultural comum. Assiste-se ao crescimento de um sentimento de ódio e/ou raiva perante uma situação que se apresenta discriminatória. A veemência e a violência quase pornográfica de alguns rappers consegue transmitir a profunda indignação desta juventude relegada, banida da sociedade, e brandir o seu dedo acusador de um sistema que consideram injusto. $\mathrm{O}$ apelo à insurreição aparece com frequência associado à súplica pelo seu reconhecimento, pelo reconhecimento das suas dificuldades $^{13}$. O "respeito", eis o âmago da reivindicação ${ }^{14}$. É acima de tudo respeito que é exigido. É, pois, contra uma violência simbólica, proveniente do Estado, que a violência urbana concreta em traços gerais e as violências urbanas em particular se projectam (BAILLET, 2000, p. 25). ${ }^{15}$ Todos os representantes da autoridade estão na sua mira, podendo o conflito eclodir a qualquer momento. Bastará que se instale a desconfiança e haja uma quebra de confiança entre aqueles jovens e os garantes da ordem pública. É o que sucede em relação a instituições tão diferentes mas, em simultâneo, tão semelhantes como são a escola e a polícia. A escola, meio de integração republicana e de socialização por excelência, falhou aqui ao não conseguir essa mesma integração. Para muitos jovens provenientes da imigração, a escola não é mais do que a "escola da colonização", ou seja, da aculturação e da assimilação

\footnotetext{
13 "Niquer l'système, ils auront le feu car ils ont semé la haine, / Qu’on les brûle, qu'on les pende ou qu'on les jette dans la Seine, / La jeunesse du ghetto a la rage qui coule dans les veines, / Il faut brisé les chaînes." Refrão da música " Nique le système », de Bakar (feat. Eben, Tandem; Sniper).

14 “On nous fait des promesses, pour qu'on se calme. Mais c'est pas des salles de sports qu'on veut, mais une reconnaissance de la société, du « respect »." (RICORDEAU, 2001, p. 174). "Mourad va ainsi tenter d'expliquer pourquoi ce qui était possible autrefois dans la génération des pères - le travail abrutissant, la surexploitation, la soumission, la docilité, léchine souple - ne l'est plus aujourd'hui dans la génération des fils, en quête de fierté retrouvée, de « respect »" (BEAUD \& PIALOUX, 2002, p. 237).

15 "La violence symbolique et la violence plus concrète sont analytiquement distinctes mais se combinent sans cesse [...]. Elles s'alimentent et s'interpénètrent, ce qui interdit de se contenter de les distinguer. Il s'agit bien, plutôt, de les penser simultanément dans leur différence théorique et dans leurs combinaisons historiques." (WIEVIORKA, 1999, p. 17).
} 
forçada (BAILLET, 2000, p. 20) ${ }^{16}$. Quem não conseguisse corresponder-lhe positivamente estaria condenado a um destino semelhante ao dos seus pais. E, como foi indicado, este tem que ser imperiosamente evitado. Porém, a acusação de que aquela estaria a priori condicionada, discriminando de forma negativa os jovens de origem magrebina e africana, contraria o princípio de igualdade republicana. A crença na integração pela cidadania foi-se desvanecendo em largas camadas desta população. Daí a acreditar que este conceito de “integração" era uma farsa foi um passo, a despeito dos casos de sucesso ${ }^{17}$. Jovens franceses de origem norte-africana e sub-sahariana sem qualificação académica viram ser-lhes progressivamente fechadas todas as portas, da escola às instituições republicanas, até ao próprio emprego. É de referir que estes não pretendem uma mudança do sistema mas sim a sua reestruturação e a real aplicação dos valores da República ${ }^{18}$. Analisadas sob este prisma, as violências urbanas à la française, incluindo as que assumem feições anti-institucionais, não se pretendem uma afronta ao Estado e à ordem pública mas sim uma expressão mais radical do desregulamento social (COLLOVALD, 2001, p. 110). Segundo Alain Bauer, esta situação é natural. O sistema social francês traz

${ }^{16}$ Note-se que a teoria política colonial francesa reconhecia quatro formas de relações coloniais: a sujeição, a autonomia, a assimilação e a associação. De entre estas, foi dada primazia à assimilação como concretização daquilo que Boaventura de Sousa Santos denomina de universalismo antidiferencialista. Segundo ele, "O dispositivo ideológico de gestão da desigualdade e da exclusão é o universalismo, uma forma de caracterização essencialista que, paradoxalmente, pode assumir duas formas na aparência contraditórias: o universalismo antidiferencialista que opera pela negação das diferenças e o universalismo diferencialista que opera pela absolutização das diferenças. [...] Se o primeiro universalismo permite a desigualdade e a exclusão pelo excesso de semelhança, o segundo permite-as pelo excesso de diferença." (Santos, 2006, p. 263) No período colonial, "...if it does not fit, the fault is with the natives, not the code. Let them conform or hear the other agent of French colonization, the rattle of the mitrailleuse." (ROBERTS, 1963, p. 67).

17 " [...] les jeunes révoltés ne demandent pas à être reconnus comme une minorité avec ses droits et ses spécificités. Ils ont cru au modèle français d’intégration par la citoyenneté. Ils voulaient être de vrais Français mais ils se considèrent comme trompés parce qu'aujourd'hui ils ne sont français que sur le papier. Ils protestent dans le fond contre l'échec de l'intégration à la française, mais ils n’ont pas d'autres modèles." (ROY, 2005).

${ }^{18} \mathrm{O}$ rap possibilita uma certa radicalização de posições. Tal é visível no refrão da música «La France » do grupo Sniper : "La France est une garce et on s'est fait trahir / Le système voilà ce qui nous pousse à les haïr / La haine c'est ce qui rend nos propos vulgaires / On nique la France sous une tendance de musique populaire / On est d'accord et on se moque des répressions / On se fout de la république et de la liberté d'expression / Faudrait changer les lois et pouvoir voir / Bientôt à l'Elysée des arabes et des noirs au pouvoir." 
no seu seio o gérmen da violência, simultaneamente desesperada e criativa ${ }^{19}$, e o conflito é portanto estrutural (MUCCHIELLI, 1999, p. 22).

\section{Entre prevenção e repressão}

Existem, dependendo de quem observa estas violências urbanas, diferentes formas de interpretá-las. Assim, a população dos subúrbios, directamente afectada pelos actos de vandalismo e de destruição dos bens públicos (escolas, esquadras, centros sociais e culturais) e privados (incêndio de automóveis), adopta uma atitude dualista. Se, por um lado, existe uma condenação firme do recurso à força e à violência como meio de reivindicação e de manifestação do descontentamento latente; por outro lado, e em particular nas famílias de imigração, há uma recusa em condenar os jovens autores daqueles actos e, inclusive, uma certa desculpabilização dos mesmos devido à subsistência de circunstâncias atenuantes (o desemprego, o racismo, a discriminação) ${ }^{20}$. Estas estão plenamente conscientes da importância deste tipo de acções para a mediatização das dificuldades vividas pelos habitantes de certo subúrbio e, com isso, obterem respostas aos seus protestos.

Para aqueles que suportam, no seu quotidiano, as violências urbanas e não têm nenhuma ligação afectiva aos seus autores, sobrepõe-se um sentimento de injustiça e de frustração perante uma certa passividade das forças da ordem. A esses, apresentam-se duas soluções. A primeira consiste na adopção de uma estratégia de distanciamento ou retraimento; a segunda tem a ver com o aperfeiçoamento de estratégias conflituosas defensivas (BAILLET, 2000, p. 23).

19 "Notre système social a toujours été producteur de violence, parfois simplement pour lutter contre une oppression plus grande encore. Une partie de cette violence est créatrice. Une autre, parce que désespérée, ne dépasse pas le niveau de la destruction." (BAUER, 2000, p. 200).

20 "Dans cette colère vengeresse des jeunes durant les émeutes, que leurs parents et leurs grands frères disent souvent désapprouver sur la forme mais comprendre sur le fond, l'on peut peut-être lire ainsi une dimension plus collective encore." (CRETTIEZ \& SOMMIER, 2006, p. 35). Cf. (BEAUD; PIALOUX, 2002, p. 223) e (BEAUD; PIALOUX, 2005, p. 8). 
Quanto ao Estado, a ênfase é colocada, não tanto no carácter reivindicativo das violências urbanas, mas sim no seu aspecto criminal, anti-institucional e até insurreccional. Certos autores designam o conflito opondo os jovens dos subúrbios às forças da ordem de "Guerra à polícia" ou ainda de "Intifada Francesa" ou "Intifada das banlieues" (MONIQUET, 2005; ROY, 2005), aliando a esta noção outras que permitem colocar em causa a subsistência da ordem pública nestes territórios (intimidação, Omertà, terror, ...) (BAUER \& RAUFER, 2001, p. 28-32). O pânico e o medo acabam por se espalhar à população em geral, agravando-se com as imagens transmitidas pela comunicação social que estigmatizam e condenam ao ostracismo os subúrbios e os seus jovens. Parecerá que a aproximação ao conceito de "novíssimas guerras" faz todo o sentido. E, à semelhança do que acontece em espaços encarados como palcos dessa manifestação violenta, a República recusa abdicar do seu papel civilizador e organizador da vida em sociedade. Os seus símbolos estão presentes nas banlieues e estas são alvo de políticas específicas e adaptadas a cada situação. ${ }^{21}$ Com maior ou menor sucesso, a política de prevenção, associando e articulando reestruturação urbana, revitalização económica e projecto social, perdura. Assim, e de momento, não existem, em França, zonas proibidas às forças da ordem ou deliberadamente abandonadas e onde a sua presença se limita a acções repressivas relâmpago (BODY-GENDROT, 1995, p. 194). A novidade é o realce dado à segurança (BODY-GENDROT \& DUPREZ, 2001, p. 386). A questão que se coloca é saber qual o tipo de prevenção mais adequada à situação. A realidade é que a opinião pública interiorizou o mito do medo e do desvio social em referência aos subúrbios urbanos. Exacerbado pelo pavor do terrorismo islamita e pelos excepcionalmente longos motins do Outono de 2005, criou-se um certo sentimento de insegurança e de crença no fracasso do modelo de integração republicana e da própria República.

A teoria dos vidros partidos, de James Q. Wilson e George L. Kelling ([S/d]) afirma que a desordem, o crime e, por conseguinte, o sentimento de insegurança se devem a uma sequência de factos. Segundo eles, a existência de uma janela partida num prédio e a sua subsistência nesse estado durante algum tempo conduz à

21 "Les sigles barbares (QHD, DSU, DSQ, ZUS, ZFU, ZRU, CAPS, PLS, PDS, PDPD, ZEP) se sont ajoutées les uns aux autres selon la logique de capharnaüm.” (BAUER, 2000, p. 199). 
destruição das restantes janelas. Tal justifica-se pela persistência de uma situação contrária ao que seria habitual, a saber uma janela partida por arranjar, isto é, a não importância dada à existência dessa mesma janela partida significa que ninguém se importará com mais janelas partidas. Wilson e Kelling defendem, pois, que é esta experiência do no one caring que, em última instância, conduz à proliferação de comportamentos desordeiros, à instalação do crime e ao sentimento de insegurança que daí advém. Note-se que esta é apenas uma metáfora utilizada por estes dois autores acerca do problema causado pelas incivilidades no âmbito das violências urbanas. Não será fortuita a capacidade que o citadino tem em reconhecer, no espaço de segundos, os sinais de perigo que o espaço envolvente lhe transmite ${ }^{22}$. Pequenos indícios como o vidro partido ou um tag na parede de um prédio, assim como um barulho estranho, fazem parte de um conjunto alargado de sinais que lhe possibilitam esse reconhecimento. Uma das soluções que Wilson e Kelling apresentam como forma de atenuar esta situação é, naturalmente, a reparação dos vidros partidos, complementada pela presença de uma polícia de proximidade, conhecedora da realidade local e integrada na comunidade que serve. Não respondendo com grande eficácia à criminalidade, esta reduz bastante o sentimento de insegurança. Porém, o deslizamento progressivo de uma justiça optimista, que distingue prevenção de repressão, para uma justiça pessimista, em que ambas se misturam $^{23}$, parece ser o caminho adoptado. O discurso securitário sobrepõe-se a qualquer outro e oculta, ainda que parcial e temporariamente, as verdadeiras causas das violências urbanas e dos motins enquanto sua expressão máxima. É o desejo de separar o trigo do joio. Para tal se conseguir, formulou-se o conceito de "violências urbanas" como foi previamente exposto. Os RG orientam, pois, parte da sua actividade para a observação e a vigilância destas "novas" ameaças, desde a

\footnotetext{
22 "Independentemente dalle informazioni preventive, l'uomo metropolitano ha sviluppato una nuova capacità de riconoscere i segnali di pericolo, presunto o vero che sia. Una volta che si sia in possesso del codice e della motivazione all'ascolto, lo spazio della città è in grado di inviare segnali tempestivi di pericolo. L'uomo metropolitano dispone di un early warning system che, reagendo immediatamente a segnali ottici e sonori, anche levi, è in grado di attivare tempestivamente le difese." (AMENDOLA, 2003, p. 218).

23 "Ces deux justices renvoient à deux conceptions antinomiques de la nature humaine : l'une, éducative, fait prévaloir l'intelligence sur le dressage; l'autre, punitive, pose que l'homme comporte indissolublement une part mauvaise. Elle préconise sa mise au pas, son encadrement social et sévère, non son autonomie et son épanouissement." (CESPEDES, 2002, p. 21).
} 
organização socio-económica paralela que se desenvolve em determinados bairros até às suas ligações com a imigração, a delinquência e o Islão (BONELLI, 2001, p. 102), esquecendo-se que motins e outras facetas deste tipo de violência não são uma prerrogativa de determinados grupos étnicos e religiosos, ainda que estes estejam mais envolvidos. Até hoje, a reivindicação ou a afirmação de uma identidade étnica tem sido inexistente. Isto contraria a visão erradamente apresentada por uma grande fatia da comunicação social de outros países para quem os motins urbanos eram a reprodução das revoltas dos ghettos norte-americanos.

Tem-se, portanto, vindo a assistir ao fortalecimento de uma política de "tolerância zero", afirmação máxima da utilidade de uma repressão legal. Será esta uma forma de ascensão oculta de um Estado policial e penal, em que delinquentes e outros marginais surgem associados aos invasores estrangeiros? (ROCHÉ, 2002, p. 63). Historicamente, as periferias das cidades simbolizaram sempre uma certa barbárie, cristalizando o terror perante o inimigo interno. Hoje como ontem, os seus habitantes, não conformes às regras da sociedade, são retratos sob a feição do estrangeiro $^{24}$. A necessidade de controlo social aparece aos olhos dos governantes como imprescindível. Nicole Gonthier, ao estudar a violência nas cidades medievais, apresenta como um grande obstáculo às tentativas de integração do estrangeiro o medo e a suspeição, não sendo viável a sua reabilitação ou reintegração na sociedade dado o desconhecimento que se tem do seu passado ${ }^{25}$. Hoje em dia, o principal argumento contra o estrangeiro baseia-se em meras questões culturais raciais e culturais, diferenciando-nos desse outro, diferente, que se desconhece (SASSEN, 1999, p. 135). São estes mecanismos que levam a que o medo do inimigo

\footnotetext{
24 "Ils rassemblent trois groupes d’individus : "des étrangers de l'intérieur", Gitans, des "étrangers de l'extérieur", jeunes d’origine maghrébine et africaine, et des "étrangers de partout", jeunes d’origine française, laissés pour compte de la grande paupérisation, ...” (BAILLET, 2000, p. 19).

25 “[... l'hostilité aux étrangers se fait plus vive lorsque des particularités religieuses et ethniques les différencient du reste des habitants." (GONTHIER, 1992, p. 70-71).

"Létranger, le "forain" [...] devient un élément de suspicion lorsqu'il n’appartient pas au groupe des migrants qui s'installent, qui s'intègrent dans les liens de voisinage et participent à l'économie de la ville. [...] La justice ne laisse pas une seconde chance à létranger, non plus qu’on ne tente de le "réhabiliter" ou de réintégrer dans la société, car l'ignorance où l'on est de son passé permet de l'imaginer chargé de crimes nombreux." (GONTHIER, 1992, p. 205).
} 
interno se concretize no nascimento, multiplicação e reforço das cidades blindadas e dos edifícios fortalezas, ou ainda das Gated Communities (LE GOIX, 2001), por oposição aos subúrbios e às periferias. Jean-Pierre Garnier, sociólogo especialista da arquitectura, refere-se à cidade contemporânea como um espaço indefensável. Segundo ele, a arquitectura tem um papel importante no âmbito da conflitualidade urbana. Deste modo, passou-se da existência de espaços criminalizantes para espaços cúmplices dos criminosos e hostis à forças da ordem (GARNIER, 2010, p. 6). Quanto ao espaço público, central, cada vez mais se vai tornando um espaço policiado, do qual os indesejáveis e os "visitantes" não motivados são mantidos afastados através de uma série de mecanismos dissuasores, físicos e simbólicos (videovigilância, empresas privadas de segurança, ...). A cidade aparece, portanto, muito próxima da ideia do panóptico benthamiano. Baseando-se no exemplo norte-americano, Giandomenico Amendola apresenta uma tipologia do espaço público selectivo deveras curiosa. Assim, existirão cinco tipos de espaços, a saber: o espaço invisível (ou Stealthy space), o espaço labiríntico, o espaço blindado, o espaço incómodo e o espaço ansiógeno ${ }^{26}$.

O tradicional cosmopolitismo urbano enquanto fonte de criação e gerador de conflitos, que se traduz simultaneamente numa harmoniosa coexistência de culturas e no seu confronto, encontra-se hoje num impasse delicado. Céline Sachs-Jeantet ([S/d], p. 6) refere-se, a este respeito, a uma urbanidade deslocada, consequência de um processo de transformação dos valores inerentes à própria noção de cidade. De cosmopolita, tolerante e integradora, esta é hoje exclusiva, racista e violenta.

26 "Le principali tipologie dello spazio pubblico selettivo sono :

a) lo spazio difeso dall'invisibilità (Stealthy space): uno spazio che, camuffato o nascosto, è difficile trovare. [...]

b)lo spazio difeso dal labirinto: le vie par raggiungerlo sono complicate e talvolta sono dei vicoli ciechi che riportano il visitatore non iniziato e, comunque, casuale al punto di partenza. [...]

c) lo spazio blindato: racchiuso da barriere tanto pratiche che simboliche, come reti, cancelli o porte enfaticamente sorvegliate, che scoraggiano il visitatore non motivato. [...] d) lo spazio disagevole: occuparlo può essere unautentica impresa per i mezzi di dissuasione in esso collocati. [...]

e) lo spazio ansiogeno: una sorveglianza continua dà al visitatore la sgradevole sensazione di essere sempre sotto controllo [...]" (AMENDOLA, 2003, p. 222-223). 
Todavia, estas medidas remetem para uma gestão interna do estrangeiro, do inimigo cuja presença não se pode debelar com facilidade. É, de igual modo, fundamental gerir o perigo na sua origem, o que se consegue através de eficazes políticas de imigração cujo objectivo é o seu controlo através da sua limitação. Veja-se a título de exemplo o projecto de lei relativo ao controlo da imigração, à integração e ao asilo ${ }^{27}$ apresentado pelo Ministério da Imigração, da Integração, da Identidade Nacional e do Co-desenvolvimento francês na Assembleia Nacional em 2007. Este vem, de facto, concretizar de uma forma muito clara aquele desígnio. O artigo L. 411-8, que este projecto de lei pretende acrescentar ao Code de l'Entrée et $d u$ Séjour des Etrangers et du Droit d'Asile, agrava as condições do reagrupamento familiar. O conhecimento da língua e dos valores da República (nomeadamente a monogamia, a igualdade entre sexos, o respeito pela liberdade do casamento, ...) passam a ser condições imprescindíveis para a sua concretização. ${ }^{28}$ Em 2010 viu o dia o sexto projecto de lei relativo ao controlo da imigração, à integração e ao asilo ${ }^{29}$. Este introduz um novo aspecto que vem condicionar o acesso à nacionalidade francesa ao exigir aos candidatos à naturalização a assinatura de uma carta de direitos e deveres do cidadão. Com este acto, aqueles firmam um contrato que vai para além do mero conhecimento dos princípios e valores republicanos, como acontecia até aí. Esta carta implica a aceitação e a aplicação dos mesmos, sendo que a quebra deste contrato é penalizada com a perda da nacionalidade adquirida. Note-se que a assinatura da carta é o resultado de uma "entrevista de assimilação" levada a cabo por entidades policiais. Em resumo, este último projecto de lei cria

${ }^{27}$ Cf. Projet de loi relatif à la maîtrise de l'immigration, à l'intégration et à l'asile (4 juillet 2007).

28 "Art. L. 411-8. - Pour lui permettre de préparer son intégration républicaine dans la société française, le ressortissant étranger de plus de seize ans pour lequel le regroupement familial est sollicité bénéficie, dans son pays de résidence, d'une évaluation de son degré de connaissance de la langue et des valeurs de la République. Si cette évaluation en établit le besoin, l'autorité administrative organise à l'intention de l'étranger, dans son pays de résidence, une formation dont la durée ne peut excéder deux mois. Le bénéfice du regroupement familial est subordonné à la production d'une attestation de suivi de cette formation, dans des conditions fixées par décret en Conseil d'État. Ce décret précise notamment le délai maximum dans lequel la formation doit être proposée et les motifs légitimes pour lesquels l'étranger peut en être dispensé." In Projet de loi relatif à la maîtrise de l'immigration, à l'intégration et à l'asile (4 juillet 2007).

${ }^{29}$ Cf. Projet de loi relatif à la l'immigration, à l'intégration et à l'asile (31 mars 2010). 
duas categorias de cidadãos de acordo com a natureza da sua nacionalidade (de origem ou adquirida). Assim, àqueles que nascem franceses nunca será exigida a assinatura da carta de direitos e deveres do cidadão. Aos outros, esta será imposta como uma condição sine qua non para adquirirem o estatuto de "bom" francês, ou francês de direito.

\section{As violências urbanas: excepção francesa ou novíssima guerra?}

Para voltar à ideia de "novíssimas guerras", parece irrealista incluir a situação que se vive em França no mesmo saco que as violências que pautam o dia-a-dia de São Paulo, do Rio de Janeiro ou de qualquer outra metrópole da América Latina. Não se pretende com isto dizer que os casos são totalmente diferentes quanto às suas características. Contudo, a realidade local, assemelhando-se em alguns aspectos importantes como seja a existência de um culto da violência, diverge num ponto fundamental que é o grau de violência directa e as taxas de mortalidade por armas de fogo elevadas, inexistentes no contexto francês numa intensidade tão grande como as existentes noutros contextos. A República poderá, isso sim, ter falhado, nomeadamente em termos de integração, com consequências gravíssimas em termos de (in)segurança. Tal não conduz, porém, invariavelmente à conclusão de que está perante uma "novíssima guerra", ainda que o futuro possa caminhar nesse sentido caso os mecanismos estatais falharem na procura da resposta adequada ${ }^{30}$. Até ao momento, as violências urbanas que assolam a totalidade do território nacional francês têm-se limitado a conflitos esporádicos opondo os seus autores às forças da ordem e outros representantes da autoridade. Os confli-

\footnotetext{
30 "La question à laquelle se trouvent ainsi confrontés les pays du Premier monde à l'orée du nouveau siècle est de savoir si leurs systèmes politiques sont capables de freiner la tendance à la contradiction et à la fragmentation de la sphère de la citoyenneté, et quelles nouvelles instances de médiation il leur faut inventer afin d'y donner accès et de stimuler la participation de leurs membres. Sans quoi on pourrait assister non seulement à la pérennisation des désordres urbains, de la violence collective et des conflits ethniques (ou perçus comme tels) au cœur des sociétés avancées, mais aussi à un processus durable de fission sociale et de propagation des inégalités et de l'insécurité s'apparentant à une véritable " brésilianisation " des métropoles d'Europe et d'Amérique du Nord." (WACQUANT, 2006, p. 43-44).
} 
tos entre gangs também existem, mas não atingem graus de violência similares aos da América Latina. Aliás, uma das suas características é a visibilidade desses grupos armados que, opondo-se à ordem pública sem a substituir formalmente, instituem a sua própria ordem ao bairro ou subúrbio. Tal não é aqui o caso. Quanto a confrontos étnicos, à semelhança das violências intercomunitárias que têm tido lugar em Inglaterra (Bradford e Oldham, Verão de 2001; Birmingham, Outubro de 2005), foi aqui apresentada uma visão contrária ${ }^{31}$. Apesar de as autoridades teimarem na definição das violências urbanas à la française enquanto expressão de uma sublevação de grupos étnicos específicos, a realidade demonstrou que esta característica não pode ser desligada de critérios socio-económicos. As banlieues não são ghettos no verdadeiro sentido da palavra. Contrariamente a posições defendidas com frequência, não existem grandes similitudes entre a cintura negra das cidades norte-americanas e a antiga cintura vermelha das urbes francesas para além de serem comummente consideradas pelas sociedades nacionais em que se inserem antros de violência e de criminalidade a evitar. À homogeneidade étnica dos ghettos norte-americanos opõe-se, por exemplo, a multiculturalidade das banlieues das cidades francesas. Isto conduzirá a uma classificação destas violências urbanas enquanto especificas do contexto francês? Uma resposta positiva seria francamente desonesta. Algumas das características que aqui se encontram estão de igual modo presentes noutros contextos. O facto que dá origem ao motim, a exclusão socio-económica e política assim como uma forte dimensão anti-institucional existem fora de França (CAS, 2006, p. 2-3). Todavia, há certas especificidades que merecem ser salientadas. Contrariamente ao que acontece noutros países, o fenómeno das violências urbanas à la française, depois dos motins do Outono de 2005, aparecem dispersas por todo o território e prolongadas no tempo. Este foi, contudo, um caso excepcional. Em comparação a outros fenómenos de violência urbana, a saber os motins de Brixton (Reino Unido, Abril de 1981) e de Los Angeles (EUA, Abril de 1992), os estragos materiais assim como o número de feridos e de mortos são inferiores. Para uma duração de vinte e quatro noites, os motins do Outono de 2005 causaram prejuízos na ordem dos 150 milhões de euros (numa média de 6 milhões

31 "Les émeutes pointent un manque de reconnaissance, l'existence d'une société multiculturelle qui vit dans le déni de cette réalité, un déficit de participation au sens d'une inclusion institutionnelle et politique des minorités." (LAGRANGE \& OBERTI, 2006, p. 130). 
por dia), para 7,5 a 11 milhões em Brixton ( 3 dias, $\approx 4$ mil. p/dia) e 347 a 446 milhões em Los Angeles ( 6 dias, $\approx 58 \mathrm{mil}$. p/dia). O número de membros das forças da ordem feridos em França durante o período referido é de 149, em oposição aos 400 de Brixton e os 3.000 feridos e 52 mortos em Los Angeles. Pode-se verificar que o grau de violência interpessoal no âmbito das violências urbanas francesas fica muito aquém do que sucede noutros contextos e conduz a que, não sendo um caso único, as violências urbanas francesas tenham as suas especificidades.

Historicamente, é visível a tradição de contestação social violenta em França. Desde a Revolução de 1789 até aos motins do Outono de 2005, passando pelo Maio de 68, todas estas manifestações de descontentamento popular resultaram em actos de violência contra o Estado. Curiosamente, se atentarmos na obra Les morts violentes en France depuis 1826. Comparaisons internationales, de Jean-Claude Chesnais (1976, p. 167-169), e não descurando a antiguidade da obra, podemos verificar que o autor distingue três formas centrais de conflitos: as guerras coloniais, as civis e as revoluções, e as guerras internacionais e mundiais. Focando-nos em exclusivo nas guerras civis e nas revoluções, observamos que o autor nos apresenta três insurreições populares (1830: as Três Gloriosas mais a persistência de motins e atentados contra o monarca até 1835; 1848: revolta operária em Paris; e, a revolução de 1851). Todas elas se soldaram pela morte de um elevado número de insurrectos, respectivamente 4.500, 6.000 e 1.000, a que se lhe somam as mortes no seio das forças governamentais. Durante os meses em que vigorou a Comuna de Paris (de 18 de Março a 27 de Maio de 1871), sabe-se que o número de mortes é elevado sem, contudo, se poder precisar um número. Finalmente, já no século XX, as lutas intestinas tiveram sempre um número muito reduzido de mortes (15 durante as manifestações de 1934 e 3 durante o Maio de 68). Nos motins do Outono de 2005, com excepção das duas mortes que incendiaram os subúrbios franceses, mais nenhuma morte foi de lamentar. Será este factor de descurar numa possível classificação das violências urbanas à la française enquanto "novíssima guerra"? O mesmo Jean-Claude Chesnais interroga-se, numa outra obra da sua autoria (1981), sobre a violência que se vive, actualmente, nas cidades do Ocidente (ou do Norte), e coloca em questão o sentimento de insegurança que sente o cidadão de hoje, em contraposição com o que sucedia cem anos atrás. É interessante verificar que, referindo-se à cidade contemporânea, Chesnais refere que não é hoje necessário 
andar armado para atravessar uma qualquer cidade ou para se sentir seguro (salvo raras excepções como sejam a noite ou os bairros considerados perigosos), afastando desta forma parte do "mito" da cidade insegura.

Voltando ao que aqui nos trouxe, julgo que a maior dificuldade, na classificação deste tipo de violência enquanto novíssima guerra, reside na percepção mais intimista e condicionada que o habitante-cidadão do Norte tem acerca das periferias. Esta encontra-se a priori viciada, contaminando por conseguinte o resultado na maioria dos casos. É do Sul que vem o perigo e o Sul é o lugar de todos os perigos. Assim, no que diz respeito às violências urbanas à la française, e de forma a conseguir integrá-las num fenómeno mais global como é a conflitualidade urbana a nível mundial, proporia o desenvolvimento de uma estratificação no âmbito do conceito de novíssimas guerras. Não pretendo com isto transformar essa mesma noção numa mera hierarquização das violências urbanas. Na minha opinião, é necessário, isso sim, fazer-se a sua integração em categorias específicas dadas as diferenças inerentes a cada uma das suas manifestações locais (actores, intensidade, duração, evolução histórica ...).

\section{Conclusão}

Não se integrando, na minha opinião, na conceptualização realizada por Tatiana Moura acerca do fenómeno que ela define como sendo "novíssimas guerras", as violências urbanas à la française não fogem a uma proliferação de nichos de violência localizada nas periferias das cidades. Estas violências têm as suas raízes nas reivindicações de uma população que se sente abandonada pela República e pelas suas instituições. À integração e à igualdade republicanas sobrepuseram-se a exclusão e a discriminação social e étnica. $\mathrm{O}$ recurso à violência por parte destes jovens marginalizados afigura-se o único meio de reorientar o olho perscrutador do Estado para os seus territórios esquecidos. A República tem, por seu lado, adoptado uma postura simultaneamente preventiva e repressiva. $\mathrm{O}$ desenvolvimento das suas zonas negras tem sido alvo de políticas específicas e adequadas a cada caso. E, a repressão vê surgir o espectro de um Estado policial, controlador e discriminador. É a vitória de um sentimento de insegurança que teme uma invasão vinda de dentro. O que se procura acima de tudo evitar é o nascimento de vários 
Terceiros Mundos no seio do Norte, depositário da ordem social e da segurança. O desafio das políticas de prevenção francesas consiste portanto numa integração republicana conseguida. Apenas esta, enquanto elemento agregador pela cidadania significará que se atingiu a meta desejada. Porém, o multiculturalismo urge e, associado a ele, uma reinvenção da(s) política(s) urbana(s) e das políticas sociais.

A existência e a proliferação da criminalidade organizada nas banlieues francesas, sendo preocupante, não assume proporções tão drásticas como as existentes noutros contextos. A vida da comunidade persiste quase inalterada perante esta situação e o medo aliado ao sentimento de insegurança, apesar de existente, não impede a população destes territórios de levar a cabo uma vida normal.

Em jeito de conclusão, verifica-se que as violências urbanas à la française não se podem, actualmente, integrar num rol mais alargado como sejam as "novíssimas guerras". As especificidades locais, juntamente com uma evolução histórica distinta, conseguem afastar esse espectro deveras brutal. Todavia, e caso a resposta estatal a este problema se revele inadequada, existe essa possibilidade, ainda que longínqua. Não se pode esquecer o facto de a violência social constar do legado de séculos de luta, combate e, inclusive, insurreição do povo francês contra o Estado, a face visível do perpetrador e perpetuador de desigualdades socio-económicas.

\section{Urban violences in France: exception or newest war?}

\section{Abstract}

News about riots in French cities suburbs are nowadays frequent. This article aims to critically analyse the issue of urban violence (in the plural) in the French context in relation to the concept of "newest wars" developed by Tatiana Moura. Through their definition as well as the examination of structural deficiencies and the observation of the attitudes toward them, the article reveals the specificity of these urban violences à la française.

Keywords: Urban violences. France. Newest war. 


\section{Referências}

AMENDOLA, Giandomenico. La città postmoderna. Magie e paure della metropoli contemporanea. Roma: GLF Editori Laterza, 2003.

AVENEL, Cyprien. Sociologie des quartiers sensibles. [S.l.]: Armand Colin, 2004.

BACHMANN, Christian; LE GUENNEC, Nicole. Violences urbaines: ascension et chute des classes moyennes à travers cinquante ans de politique de la ville. Paris: Hachette Littératures, 2002.

BAILLET, Dominique. Les incivilités, en paroles et en actes. Hommes \& Migrations. v. 1227, p. 16-25, 2000.

BAKAR. Pour les quartiers. [S/l]: Kilomaitre, 2005. CD.

BAUER, Alain. Sécurité et insécurité urbaines. In : MICHAUD, Yves (Dir.) Qu’estce que la société ? Paris: Odile Jacob, 2000. v. 3.

BAUER, Alain; RAUFER, Xavier. Violences et insécurité urbaines. 6. ed. Paris: Universitaires de France, 2001.

BAUER, Alain; RAUFER, Xavier; SOULLEZ, Christophe. Violences et insécurité urbaines. 10. ed. Paris: Universitaires de France, 2006.

BEAUD, Stéphane; PIALOUX, Michel. La racaille et les vrais jeunes: Critique d'une vision binaire du monde des cités. Liens socio, 2005. Disponível em: <http://www. liens-socio.org/article.php3?id_article=977>. Acesso em: 12 maio 2010.

BEAUD, Stéphane; PIALOUX, Michel. Sur la genèse sociale des "émeutes urbaines »". Sociétés Contemporaines. 45-46, p. 215-243, 2002.

BODY-GENDROT, Sophie. Villes et violence. L'irruption de nouveaux acteurs. 2. ed. Paris: Universitaires de France, 1995.

BODY-GENDROT, Sophie; DUPREZ, Dominique. Les politiques de sécurité et de prévention dans les années 1990 en France: les villes en France et la sécurité. Déviance et Société, v. 25, n. 4, p. 377-402, 2001.

BONELLI, Laurent. Renseignements généraux et violences urbaines. Actes de la recherche en sciences sociales, v. 1, n. 136-137, p. 95-103, 2001. 
CENTRE D'ANALYSE STRATEGIQUE - CAS. Les violences urbaines: une exception française?: enseignements d'une comparaison internationale. La Note Externe de Veille, n. 31, 23 oct. 2006. Disponível em: <http://www.strategie.gouv.fr/ IMG/pdf/NoteExterneDeVeille31.pdf>. Acesso em: 26 maio 2010.

CESPEDES, Vincent. La cerise sur le béton. Violences urbaines et libéralisme sauvage. [S.l.]: Flammarion, 2002.

CHESNAIS, Jean-Claude Les morts violentes en France depuis 1826. Comparaisons internationales. Paris: Universitaires de France, 1976.

CHESNAIS, Jean-Claude. Histoire de la violence en Occident de 1800 à nos jours. Paris: Robert Laffont, 1981.

COLlOVALD, Annie. Des désordres sociaux à la violence urbaine. Actes de la recherches en sciences sociales. v. 1, n. 136-137, p. 104-113, 2001.

CRETTIEZ, Xavier; SOMMIER, Isabelle (Dir.). La France rebelle. Paris: Michalon, 2006.

FISCHER, Gustave-Nicolas Psychologie des violences sociales. Paris: Dunod, 2003.

GARNIER, Jean-Pierre Un espace indéfendable. l'aménagement urbain à l'heure sécuritaire, 2010. Disponível em: <http://actes.cites.free.fr/images/ESPACE\%20 SECURITAIRE.pdf $>$. Acesso em: 13 maio 2010.

LAGRANGE, Hugues; OBERTI, Marco (Dir.). Émeutes urbaines et protestation. Une singularité française. Paris: Sciences Po, 2006.

LE GOIX, Renaud. Les « communautés fermées » dans les villes des États-Unis. Aspects géographiques d'une sécession urbaine. L’Espace géographique, v. 1, p. 8194, 2001.

MACE, Éric. Les violences dites « urbaines » et la ville. Du désordre public au conflit dans l'espace urbain Les Annales de la Recherche Urbaine, v. 83-84, p. 59-64, 1999.

MONIQUET, Dominique. La France face à une crise majeure dans les banlieues: révolte sans lendemain ou début d'une "Intifada française ». Note de Synthèse. European Strategic Intelligence and Security Center, 2005. Disponível em: $<$ http:// www.esisc.org/documents/la-france-face-a-une-crise-majeure.pdf $>$. Acesso em: 27 maio 2010. 
MOURA, Tatiana. Novíssimas guerras, novíssimas pazes. Desafios conceptuais e políticos. Revista Crítica de Ciências Sociais, v. 71. p. 77-96, 2005.

MUCCHIELLI, Laurent. L'expertise policière des "violences urbaines ", 2001. Disponível em: <http://classiques.uqac.ca/contemporains/mucchielli_laurent/ D_reflexions_actualite/expertise_policiere_violence_urbaine/expertise_pol_ violence_urb.pdf>. Acesso em: 13 maio 2010.

MUCCHIELLI, Laurent. La politique de la " tolérance zéro »: les véritables enseignements de l'expérience new-yorkaise, 2002. Disponível em: <http://classiques. uqac.ca/contemporains/mucchielli_laurent/D_reflexions_actualite/politique_ tolerance_zero/politique_tolerance_zero.pdf>. Acesso em: a 31 maio 2010.

MUCCHIELLI, Laurent. Violences urbaines, réactions collectives et représentations de classe chez les jeunes des quartiers relégués de la France des années 1990, 1999. Disponível em: <http://classiques.uqac.ca/ contemporains/mucchielli_laurent/A_ recherche_delinquance_juvenile/violences_urbaines_repres_jeunes/violences_ urbaines_jeunes.pdf $>$. Acesso em: 13 maio 2010.

NESSI, Julien. La montée en violence des mafias de banlieues in Le Figaro. 28 avril 2006. Disponível em: <http://www.lefigaro.fr/magazine/20060428. MAG000000372_la_montee_en_violence_des_mafias_de_banlieue.html >. Acesso em: 2 abr. 2010.

PIERRAT, Jérôme. La mafia des cités. [S.1.]: Denoël, 2006.

PROJET de loi relatif à la l'immigration, à l'intégration et à l'asile, 31 mars. 2010. Disponível em: <http://www.assemblee-nationale.fr/13/pdf/projets/pl2400.pdf>. Acesso em: 27 jul. 2010.

PROJET de loi relatif à la maîtrise de l'immigration, à l'intégration et à l'asile, 4 jul. 2007. Disponível em: <http://www.assemblee-nationale.fr/13/projets/pl0057.asp>. Acesso em: 27 jul. 2010.

RICORDEAU, G. Pourquoi cassent-ils? Présentation des discours et motivations des casseurs. Déviance et Société, v. 25, n. 2, p. 165-183, 2001.

ROBERT, Stephen H. The History of French Colonial Policy. 1970-1925. London: Frank Cass, 1963.

ROCHÉ, Sebastian. Tolérance zéro? Incivilités et insécurité. Paris: Odile Jacob, 2002. 
ROY, Olivier. Intifada des banlieues ou émeutes de jeunes déclassés?, 2005. Disponível em: <http://www.diplomatie.gouv.fr/fr/IMG/pdf/0501-ROY-FR-2.pdf>. Acesso em: 14 abr. 2010.

SACHS-JEANTET, Céline. Villes et gestion des transformations sociale. Un défi pour les sciences sociales, [S/d]. Disponível em: <http://unesdoc.unesco.org/ images/0010/001030/103077f.pdf >. Acesso em: 13 maio 2010.

SANTOS, Boaventura de Sousa. A gramática do tempo: para uma nova cultura política. Porto: Afrontamento, 2006.

SASSEN, Saskia. Guests and aliens. New York: The New Press, 1999.

SNIPER. Du rires aux larmes. [S/1]: East West France, 2001. CD.

WACQUANT, Loïc. Parias urbains. Ghetto, banlieues, État. Paris: La Découverte, 2006.

WIEVIORKA, Michel. Violence en France. Paris: Seuil, 1999.

WILSON, James Q.; KELLING, George L. The police and neighborhood safety. Broken Windows, [S/d]. Disponível em: <http://www.manhattan-institute.org/ pdf/_atlantic_monthly-broken_windows.pdf>. Acesso em: 27 jul. 2010. 